\title{
Clinical Utility Gene Card for: Congenital Generalized Lipodystrophy
}

\author{
Isabelle Jéru ${ }^{\star, 1,2,3}$, Camille Vatier ${ }^{2,3,4}$, David Araujo-Vilar ${ }^{5}$, Corinne Vigouroux ${ }^{1,2,3,4}$ and Olivier Lascols ${ }^{1,2,3}$
}

European Journal of Human Genetics (2016) 24, doi:10.1038/ejhg.2016.53; published online 18 May 2016

\section{DISEASE CHARACTERISTICS}

\subsection{Name of the disease (synonyms)}

There are four subclasses of Congenital Generalized Lipodystrophy (CGL), also named Berardinelli-Seip Congenital Lipodystrophy (BSCL):

Type 1 CGL (CGL1).

Type 2 CGL (CGL2).

Type 3 CGL (CGL3).

Type 4 CGL (CGL4).

It is important to underline that CGL is an expanding group of disorders, whose classification is still underway. In addition to the diseases known as CGL in OMIM, generalized lipodystrophies can be encountered in other Mendelian disorders including severe insulinresistance syndromes, complex progeroid syndromes, as well as autoinflammatory diseases. A de novo variant in the promoter of the FOS gene has also been reported in a generalized lipodystrophy, though this disease has not entered the CGL classification so far. ${ }^{1}$ The description of all these rare entities is beyond the scope of this clinical utility gene card, which will focus on the so-called CGL.

\subsection{OMIM\# of the disease}

CGL1: \#608594.

CGL2: \#269700.

CGL3: \#612526.

CGL4: \#613327.

1.3 Name of the analysed genes or dna/chromosome segments CGL1: AGPAT2.

CGL2: BSCL2.

CGL3: $C A V 1$.

CGL4: PTRF.

\subsection{OMIM\# of the gene(s)}

AGPAT2: ${ }^{\star} 603100$.

BSCL2: ${ }^{\star} 606158$.

CAV1: ${ }^{\star} 601047$.

PTRF: ${ }^{\star} 603198$.

\subsection{Mutational spectrum}

AGPAT2-CGL1 is an autosomal recessive disorder. Several dozen disease-causing variants have been described. ${ }^{2}$ The following molecular defects have been reported: nonsense, missense, splice-site variants, deletions and insertions. ${ }^{3}$ Most of them result in frameshift and/or truncated proteins, which are likely to lead to the complete loss of AGPAT2 function. This can be demonstrated in vitro by measurement of AGPAT2 enzymatic activity. ${ }^{4}$

BSCL2-CGL2 is an autosomal recessive disorder. Several dozen disease-causing variants have been described. The following molecular defects have been reported: nonsense, missense, splice-site variants, deletions and insertions. ${ }^{3,5}$ Most of them result in frameshift and/or truncated proteins, which are likely to lead to complete loss of BSCL2 function (for more details, see http://databases.lovd.nl/shared/variants/ BSCL2/unique). Notably, disease-causing variants in this gene have also been identified in patients with distal hereditary motor neuropathies or neurodegenerative syndromes. ${ }^{6}$

$C A V 1$ - disease-causing variants in this gene are very rare. A homozygous nonsense variant was identified in a patient with CGL. ${ }^{7}$ In addition, a nonsense variant, two deletions leading to frameshifts and a variant located within the $5^{\prime}$-untranslated region of the gene were reported in the heterozygous state in patients with atypical forms of lipodystrophies, either partial or generalized. ${ }^{8-10}$ Notably, diseasecausing variants in this gene have also been identified in patients described with isolated pulmonary hypertension. ${ }^{11}$

PTRF-CGL4 is an autosomal recessive disorder associating generalized lipodystrophy and muscular dystrophy. A bit more than 10 disease-causing variants have been described to date. The following molecular defects have been reported: nonsense, splice-site variants, deletions and insertions. ${ }^{12}$ All of them result in frameshift and/or truncated proteins, which are likely to lead to complete loss of PTRF function. Individuals carrying disease-causing variants in the heterozygous state can present minor signs of the disease.

Except for BSCL2, there is no specific database listing molecular defects implicated in CGL.

\subsection{Analytical methods}

Sanger sequencing of PCR products corresponding to the coding regions and conserved splice sites is performed on a routine basis. Next-generation sequencing, including gene-targeted and wholeexome sequencing approaches, is also used.

\footnotetext{
${ }^{1}$ AP-HP, Hôpital Saint-Antoine, Laboratoire Commun de Biologie et Génétique Moléculaires, Paris, France; ${ }^{2}$ Sorbonne Universités, UPMC Univ Paris 06, INSERM, UMR_S938, Centre de Recherche Saint-Antoine, Paris, France; ${ }^{3}$ CAN, Institute of Cardiometabolism and Nutrition, Paris, France; ${ }^{4}$ AP-HP, Hôpital Saint-Antoine, Service d'Endocrinologie, Diabétologie et Endocrinologie de la Reproduction, Paris, France; ${ }^{5} \mathrm{CIMUS} \mathrm{Biomedical} \mathrm{Research} \mathrm{Institute,} \mathrm{University} \mathrm{of} \mathrm{Santiago} \mathrm{de} \mathrm{Compostela-IDIS,} \mathrm{Santiago} \mathrm{de} \mathrm{Compostela,}$ Spain

*Correspondence: Dr I Jéru, AP-HP, Hôpital Saint-Antoine, Laboratoire Commun de Biologie et Génétique Moléculaires, 184 rue du Faubourg Saint-Antoine, Paris 75012, France. Tel: +33 14928 2809; Fax: +33 14928 2206; E-mail: isabelle.jeru@aphp.fr Received 23 November 2015; revised 4 April 2016; accepted 21 April 2016; published online 18 May 2016
} 


\subsection{Analytical validation}

There are several steps in the analytical validation process.

- Sequencing of both DNA strands (forward and reverse) is performed.

- When two heterozygous variants or a homozygous variant are found, testing of the patients' parents is recommended to confirm that the defect is biallelic. More generally, identification of the same variant in the affected proband's relatives provides additional confirmation of the result. When the genetic test is positive, a search of the molecular defects is also recommended on a second independent sample from the patient.

- Newly discovered variants may be searched for in databases listing benign and pathogenic variants. Pathogenicity of variants can also be tested by in silico prediction methods and functional studies.

Notably, there is to date no external quality assessment dedicated to this specific set of genes proposed by the European Molecular Genetics Quality Network.

1.8 Estimated frequency of the disease (Incidence at birth ('birth prevalence') or population prevalence. If known to be variable between ethnic groups, please report):

Less than 500 patients have been reported worldwide. The population prevalence has been estimated to be about 1 in 10 million. ${ }^{13}$

\subsection{Diagnostic setting}

\begin{tabular}{lll}
\hline & Yes & No \\
A. (Differential) diagnostics & $\bigotimes$ & $\square$ \\
B. Predictive testing & $\square$ & $\square$ \\
C. Risk assessment in relatives & $\bigotimes$ & $\square$ \\
D. Prenatal & $\bigotimes$ & $\square$ \\
\hline
\end{tabular}

\section{Comment:}

CGL is characterized by a loss of nearly all the body fat with extreme muscularity. Manifestations appear at birth or during early infancy and are associated with metabolic complications (insulin resistance with acanthosis nigricans and alterations of glucose homeostasis, hypertriglyceridaemia and hepatic steatosis).

\section{TEST CHARACTERISTICS}

\begin{tabular}{|c|c|c|c|c|}
\hline & \multicolumn{2}{|c|}{ Genotype or disease } & \multirow{2}{*}{$\begin{array}{l}\text { A: True positives } \\
\text { B: False positives }\end{array}$} & \multirow{2}{*}{$\begin{array}{l}\text { C: False negative } \\
\text { D: True negative }\end{array}$} \\
\hline & Present & Absent & & \\
\hline \multicolumn{5}{|l|}{ Test } \\
\hline Positive & $A$ & B & $\begin{array}{l}\text { Sensitivity: } \\
\text { Specificity: }\end{array}$ & $\begin{array}{l}A /(A+C) \\
D /(D+B)\end{array}$ \\
\hline Negative & C & $D$ & $\begin{array}{l}\text { Positive predictive value: } \\
\text { Negative predictive value: }\end{array}$ & $\begin{array}{l}A /(A+B) \\
D /(C+D)\end{array}$ \\
\hline
\end{tabular}

\subsection{Analytical sensitivity}

(proportion of positive tests if the genotype is present)

Depending on the quality of sequencing methods, the analytical sensitivity is close to $100 \%$ for germline variants located in coding regions and flanking intronic sequences. Single-nucleotide polymorphisms (SNPs) within PCR primer-binding sites can result in preferential amplification of a single allele and constitute a rare cause of missed variant, so that careful checking of primer-binding sites for SNPs is essential. Notably, potential deep-intronic variants, variants in promoters, large deletions and duplications would not be detected by Sanger sequencing performed on a routine basis. Next-generation sequencing allows the detection of copy-number variations.

\subsection{Analytical specificity}

(proportion of negative tests if the genotype is not present)

$100 \%$. The analytical validation described above should avoid falsepositive tests. As CGL are recessive disorders, false-positive results with two unknown sequence variations are not expected.

\subsection{Clinical sensitivity}

(proportion of positive tests if the disease is present)

The clinical sensitivity can be dependent on variable factors such as age, sex or family history. In such cases a general statement should be given, even if a quantification can only be made case by case.

When the diagnosis has been properly established based on clinical investigation, family history, imaging and biochemical results, very few negative tests are expected. Molecular testing of AGPAT2 and BSCL2 explain more than $95 \%$ of cases, ${ }^{3}$ whereas CAV1 and PTRF explain very few of them. When genetic testing is negative in a patient with symptoms evocative of CGL, differential diagnoses can be considered (please see section 3.1).

\subsection{Clinical specificity \\ (proportion of negative tests if the disease is present)}

The clinical specificity can be dependent on variable factors such as age or family history. In such cases a general statement should be given, even if a quantification can only be made case by case.

Close to $100 \%$. A precise quantification is difficult, since molecular testing of CGL genes is not performed on a routine basis in asymptomatic individuals.

\subsection{Positive clinical predictive value}

(life time risk to develop the disease if the test is positive)

The positive clinical predictive value is $100 \%$. Incomplete penetrance is extremely rare in autosomal recessive disorders and has not been reported in CGL. As mentioned previously, disease onset is at birth or during early childhood.

\subsection{Negative clinical predictive value}

(probability of not developing the disease if the test is negative)

Assume an increased risk based on family history for a non-affected person. Allelic and locus heterogeneity may need to be considered.

Index case in that family had been tested:

The negative clinical predictive value is nearly $100 \%$, although a negative test does not exclude the possibility of developing a CGL due to molecular defects in other genes that were not tested.

Index case in that family had not been tested:

Genetic testing for a clinically unaffected individual is not indicated in this situation. It would only be undertaken if a variant in a gene responsible for CGL has been identified in the proband.

\section{CLINICAL UTILITY}

3.1 (Differential) diagnostics: The tested person is clinically affected (To be answered if in 1.9 'A' was marked) 
3.1.1 Can a diagnosis be made other than through a genetic test?

\begin{tabular}{lll}
\hline No & $\square$ (continue with 3.1.4) \\
Yes & $\square$ & $\square$ \\
& Clinically & \\
& Imaging & \\
& Endoscopy & $\square$ \\
& Biochemistry & $\square$ \\
& Electrophysiology \\
& Other (please describe)
\end{tabular}

Genetic testing helps to confirm the clinical diagnosis. Indeed, CGL shares clinical features with acquired generalized lipodystrophy, severe insulin-resistance syndromes (such as Rabson-Mendenhall syndrome, Donohue syndrome or SHORT syndrome), atypical progeroid syndromes and autoinflammatory diseases. ${ }^{14,15}$

\subsubsection{Describe the burden of alternative diagnostic methods to the patient}

In typical cases, clinical diagnosis is strongly suggested by combining family history, physical examination, biochemical results and imagery. There are no invasive procedures for the patient.

\subsubsection{How is the cost effectiveness of alternative diagnostic methods to be judged?}

Clinical investigations, biochemical assays and imagery are actually used to get an accurate clinical evaluation of the patients, which is necessary for their proper management and follow-up. This does not exclude genetic testing and vice versa. Both diagnostic procedures add to the global picture.

\subsubsection{Will disease management be influenced by the result of a} genetic test?

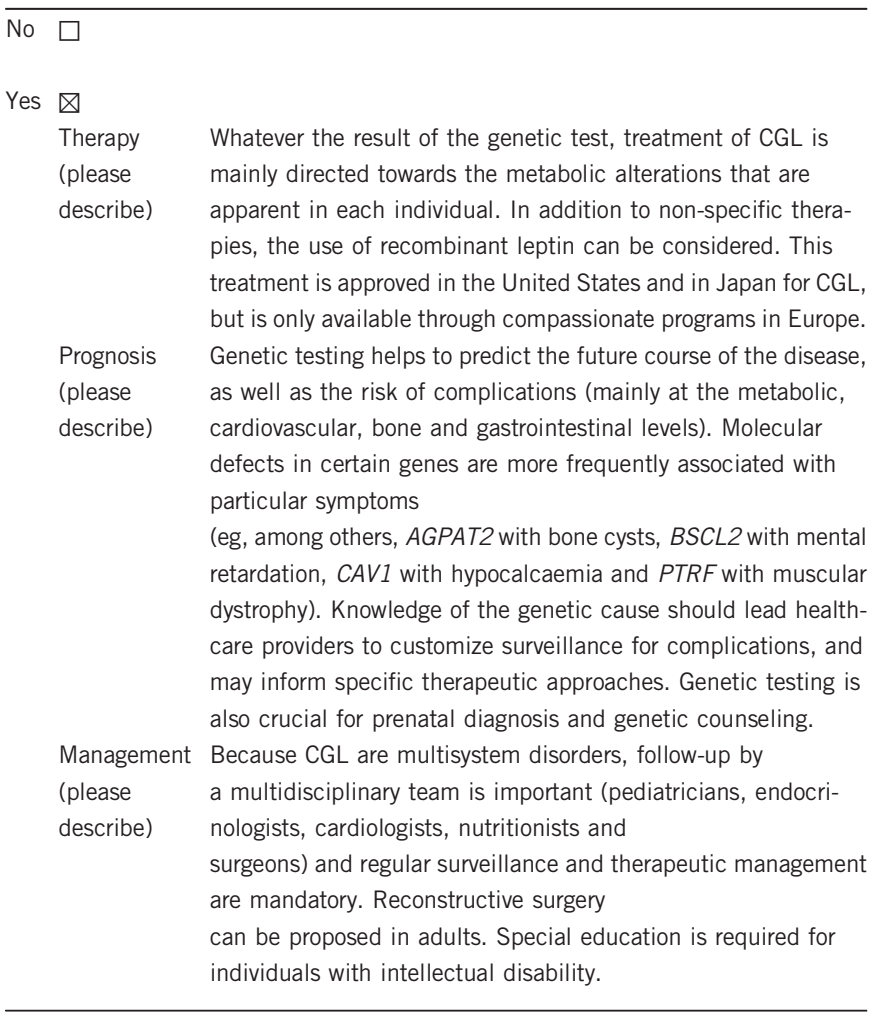

3.2 Predictive Setting: The tested person is clinically unaffected but carries an increased risk based on family history

(To be answered if in 1.9 'B' was marked)

\subsubsection{Will the result of a genetic test influence lifestyle and prevention?}

If the test result is positive (please describe):

Not applicable.

If the test result is negative (please describe):

Not applicable.

3.2.2 Which options in view of lifestyle and prevention does a person at-risk have if no genetic test has been done (please describe)?

Not applicable.

3.3 Genetic risk assessment in family members of a diseased person (To be answered if in 1.9 'C' was marked)

3.3.1 Does the result of a genetic test resolve the genetic situation in that family?

Usually yes. A positive test in a patient may lead, at adult age, to test the carriership of his/her partner.

3.3.2 Can a genetic test in the index patient save genetic or other tests in family members?

Yes.

3.3.3 Does a positive genetic test result in the index patient enable a predictive test in a family member?

No. Because CGL appears with striking manifestations, screening family members who do not display any feature of the phenotype is unnecessary.

\subsection{Prenatal diagnosis}

(To be answered if in 1.9 'D' was marked)

3.4.1 Does a positive genetic test result in the index patient enable a prenatal diagnosis?

Yes, prenatal diagnosis can be performed for parents having an affected child. It can also be proposed in the offspring of couples, in which each member carries at least one variant.

\section{IF APPLICABLE, FURTHER CONSEQUENCES OF TESTING}

Please assume that the result of a genetic test has no immediate medical consequences. Is there any evidence that a genetic test is nevertheless useful for the patient or his/her relatives? (Please describe).

Not applicable.

\section{CONFLICT OF INTEREST}

The authors declare no conflict of interest.

\section{ACKNOWLEDGEMENTS}

This work was supported by EuroGentest2 (Unit 2: 'Genetic testing as part of health care'), a Coordination Action under FP7 (Grant Agreement Number 261469) and the European Society of Human Genetics. We thank Dr David Savage (Wellcome Trust-Medical Research Council Institute of Metabolic Science, University of Cambridge, UK) for having carefully read and amended the manuscript. 
1 Knebel B, Kotzka J, Lehr S et al: A mutation in the c-fos gene associated with congenital generalized lipodystrophy. Orphanet J Rare Dis 2013; 8: 119.

2 Miranda DM, Wajchenberg BL, Calsolari MR et al: Novel mutations of the BSCL2 and AGPAT2 genes in 10 families with Berardinelli-Seip congenital generalized lipodystrophy syndrome. Clin Endocrinol 2009; 71: 512-517.

3 Agarwal AK, Simha V, Oral EA et al: Phenotypic and genetic heterogeneity in congenital generalized lipodystrophy. J Clin Endocrinol Metab 2003; 88: 4840-4847.

4 Haque W, Garg A, Agarwal AK: Enzymatic activity of naturally occurring 1-acylglycerol3-phosphate-0-acyltransferase 2 mutants associated with congenital generalized lipodystrophy. Biochem Biophys Res Commun 2005; 327: 446-453.

5 Magré J, Délépine $M$, Khallouf $E$ et al: Identification of the gene altered in Berardinelli-Seip congenital lipodystrophy on chromosome 11q13. Nat Genet 2001; 28: 365-370.

6 Guillén-Navarro E, Sánchez-Iglesias S, Domingo-Jiménez R et al: A new seipinassociated neurodegenerative syndrome. J Med Genet 2013; 50: 401-409.

7 Kim CA, Délépine M, Boutet E et al: Association of a homozygous nonsense caveolin-1 mutation with Berardinelli-Seip congenital lipodystrophy. J Clin Endocrinol Metab 2008; 93: 1129-1134.
8 Cao H, Alston L, Ruschman J, Hegele RA: Heterozygous CAV1 frameshift mutations (MIM 601047) in patients with atypical partial lipodystrophy and hypertriglyceridemia. Lipids Health Dis 2008; 7: 3.

9 Garg A, Kircher M, Del Campo M, Amato RS, Agarwal AK: Whole exome sequencing identifies de novo heterozygous CAV1 mutations associated with a novel neonatal onset lipodystrophy syndrome. Am J Med Genet A 2015; 167A: 1796-1806.

10 Schrauwen I, Szelinger S, Siniard AL et al: A frame-shift mutation in CAV1 is associated with a severe neonatal progeroid and lipodystrophy syndrome. PLOS One 2015; 10: e0131797.

11 Austin ED, Ma L, LeDuc $\mathrm{C}$ et al: Whole exome sequencing to identify a novel gene (caveolin-1) associated with human pulmonary arterial hypertension. Circ Cardiovasc Genet 2012; 5: 336-343.

12 Jelani M, Ahmed S, Almramhi MM et al: Novel nonsense mutation in the PTRF gene underlies congenital generalized lipodystrophy in a consanguineous Saudi family. Eur J Med Genet 2015; 58: 216-221.

13 Garg A: Acquired and inherited lipodystrophies. N Engl J Med 2004; 350: 1220-1234.

14 Robbins AL, Savage DB: The genetics of lipid storage and human lipodystrophies. Trends Mol Med 2015; 21: 433-438.

15 Vigouroux C, Caron-Debarle M, Le Dour C, Magré J, Capeau J: Molecular mechanisms of human lipodystrophies: from adipocyte lipid droplet to oxidative stress and lipotoxicity. Int J Biochem Cell Biol 2011; 43: 862-876. 